\title{
Intracranial aneurysms formation after radiotherapy for head and neck cancer: a 10-year nationwide follow-up study
}

\author{
Wei-Hsun Yang ${ }^{1}$, Yao-Hsu Yang ${ }^{2,3,4}$, Pau-Chung Chen ${ }^{5,6}$, Ting-Chung Wang ${ }^{1}$, Ko-Jung Chen ${ }^{3}$, Chun-Yu Cheng ${ }^{1}$ and \\ Chia-Hsuan Lai ${ }^{7^{*}}$ (i)
}

\begin{abstract}
Background: Intracranial aneurysms after radiotherapy (RT) have previously been reported. However, the majority of studies were case reports. Therefore, we performed a nationwide study to explore the risk of radiation-induced intracranial aneurysms.

Methods: This study included patients diagnosed with head and neck cancer (ICD9: 140-149, 161). Intracranial aneurysms formation was identified using the following ICD9 codes: nonruptured cerebral aneurysm (ICD9:4373), aneurysm clipping (ICD9:3951). Patients who did not receive curative treatment and those with intracranial aneurysms before the diagnosis of head and neck cancer were excluded.
\end{abstract}

Results: In total, 70,691 patients were included in the final analysis; they were categorized into the following three groups: nasopharyngeal carcinoma (NPC) with RT, non-NPC with RT, and non-NPC without RT. Patients in the NPC with RT group had the highest risk of developing intracranial aneurysms (hazard ratio (HR) 2.57; $P<0.001$ ). In addition, hypertension was also a risk factor of developing intracranial aneurysms (HR 2.14; $P<0.01$ ). The mean time interval from cancer diagnosis to intracranial aneurysm formation in the NPC with RT group was $4.3 \pm 3.1$ years.

Conclusions: Compared with the non-NPC with RT and the non-NPC without RT groups, patients with NPC who received RT had a higher risk of developing intracranial aneurysms.

Keywords: Vasculopathy, Radiotherapy, Aneurysm, Head and neck cancer

\section{Background}

Over the last century, the average life expectancy of cancer patients has increased, owing in large part to the increase in the application of radiotherapy (RT) and improvements in healthcare. With this increase in lifespan, the long-term effects of RT have become more important. Among the variety of delayed complications that occur after RT, radiation-induced vascular diseases have previously been studied [1-6]. However, the majority of studies have focused on the risk of intracranial occlusive stroke $[7,8]$ and of intracranial atherosclerosis [9].

Intracranial aneurysms formation after RT have been reported since 1967 [10, 11], usually in case reports [12-22].

\footnotetext{
* Correspondence: chiahsuan7092@gmail.com

${ }^{7}$ Department of Radiation Oncology, Chang Gung Memorial Hospital, No 6, West Section, Chia-Pu Road, Putz City, Chia-Yi, Taiwan613

Full list of author information is available at the end of the article
}

In 2000, Maruyama et al. performed a literature review that included both radiation-induced aneurysms and moyamoya vessels [23]. They concluded that radiationinduced vasculopathy was rare, but that it may be fatal. In 2014, Nanney et al. performed a literature review that focused on radiation-induced intracranial aneurysms [24]. A total of 46 patients with 69 intracranial aneurysms between 1978 and 2013 were included, and details concerning the pathologic features of the aneurysms, including fibrosis, necrosis, atherosclerotic changes, and inflammation of the aneurysmal wall, were described. However, their study had several limitations, including a limited number of cases, inconsistent diagnostic criteria, and a lack of reliable histologic and radiographic characteristics to establish a statistical model.

The association between RT and intracranial aneurysms formation continues to be debated due to varying

(c) The Author(s). 2019 Open Access This article is distributed under the terms of the Creative Commons Attribution 4.0 International License (http://creativecommons.org/licenses/by/4.0/), which permits unrestricted use, distribution, and reproduction in any medium, provided you give appropriate credit to the original author(s) and the source, provide a link to the Creative Commons license, and indicate if changes were made. The Creative Commons Public Domain Dedication waiver (http://creativecommons.org/publicdomain/zero/1.0/) applies to the data made available in this article, unless otherwise stated. 
opinions concerning the effects of radiation on vessel walls. Indeed, while previous studies demonstrated weakened vessels after radiation, Mecermott et al. [25] showed vessel thickening, which was also noted by another study $[6,26]$. Similar results were also demonstrated in other studies, which showed intimal hyperplasia, adventitia thickening, and increased connective tissue production after radiation [10, 27-32]. However, in an article investigating the outcome of 1400 patients with arteriovenous malformation treated with radiosurgery [33, 34], no intracranial aneurysms developed during an 8-year follow-up period. Therefore, the relationship between RT and intracranial aneurysms formation should be clarified.

The National Health Insurance Research Database (NHIRD) was provided by the National Health Research Institute in Taiwan. This database contains the medical claim records of 26 million individuals from 1996 to 2009, which includes almost $97 \%$ of the population of Taiwan. This database not only documents the type of cancer a patient presents, but also describes the treatment modalities used and provides long-term follow-up records. Patients with head and neck cancer have been reported to have thickened intimas and an increased rate of atherosclerotic plaque formation after RT [35]. In a study by Huang et al. that used the NHIRD, a higher risk of stroke after RT and chemotherapy was found in young patients with head and neck cancer [1]. In this study, we aimed to evaluate the risk of intracranial aneurysmal development in patients with head and neck cancer.

\section{Methods}

\section{Data source}

Data were sourced from the NHIRD. The National Health Insurance (NHI) is a compulsory universal program for all residents of Taiwan, and the NHIRD is a comprehensive healthcare database that covers nearly the entire population of Taiwan. Information concerning admissions and outpatient visits including information on patient characteristics such as sex, date of birth, date of admission, date of discharge, dates of visits, and up to five discharge diagnoses or three outpatient visit diagnoses were obtained from the database. Diagnoses were made using the International Classification of Diseases, Ninth Revision, Clinical Modification (ICD-9-CM) codes.

In this study, the Registry of Catastrophic Illness Patient Database (RCIPD) from the NHIRD was used. The RCIPD contains the medical records of all confirmed cases of catastrophic illness, including cancers, end-stage renal disease, congenital anomalies, autoimmune diseases, etc. Patients diagnosed with cancer can apply for catastrophic illness certification, and the Bureau of the NHI performs rigorous validation of all cancer diagnoses, during which at least two independent specialists review the medical, laboratory, histological, and imaging records of each patient.

\section{Ethics statement}

This study adhered to strict confidentiality guidelines in accordance with regulations regarding personal electronic data protection. It was approved by the ethics review board in our institution (No. 201700121B1). All study participants were above the legal age of consent for research of eighteen years old. All data were analyzed anonymously; the requirement for informed consent was waived by the institutional review board.

\section{Study subjects}

This study included both inpatients and outpatients diagnosed with head and neck cancer (ICD9: 140-149, 161) during 2000-2012. Patients with intracranial aneurysms prior to the diagnosis of head and neck cancer or patients with missing data were excluded. Nasopharyngeal carcinoma (NPC) patients without RT, other head and neck cancer patients who did not received surgery nor RT, patients had delayed treatment longer than three months and the patients had the prior cancer history were also excluded. All study subjects were categorized into three groups as follows: 1) NPC patients with RT (NPC-RT); 2) other head and neck cancer patients with RT (non-NPC-RT); and 3) other head and neck cancer patients without RT (non-NPC-NRT). The group of non-NPC-NRT group were used as control groups. All medical records of the study cohort during 19972013 were extracted and analyzed, and all enrolled study subjects were followed until the diagnosis of intracranial aneurysms, death, or the end of 2013.

Intracranial aneurysms were identified using the following ICD9 codes: cerebral aneurysm, nonruptured (ICD9: 4373). Patients who underwent aneurysm clipping (ICD9:3951) were also defined as having intracranial aneurysms. However, patients with intracranial spontaneous subarachnoid hemorrhage (SAH) and were in a deep coma (Glasgow Coma Scale less than six) may not receive imaging studies such as angiography or computed tomography (CT) angiography due to unstable vital signs. Therefore, these patients were not diagnosed with intracranial aneurysms. In addition, a patient diagnosed with an aneurysm may be treated with endovascular coiling instead of surgical clipping in recent years. Unlike surgical clipping, no appropriate ICD-9 codes exist for coiling. Therefore, we were unable to include patients treated with coiling or other endovascular techniques in this study.

\section{Treatments in NPC and non-NPC head and neck cancer patients}

The treatment of NPC patients was mainly radiotherapy with or without chemotherapy based on different clinical stages [36]. Most hospitals in Taiwan treated NPC 
patients with a uniform RT dose that ranged from 66 to 72 Gy [37-39].

For oral cavity cancer patients, surgery played the most important role in multidisciplinary treatments in Taiwan [36]. Most patients with resectable disease received radical surgery followed by adjuvant RT or CCRT if there were high risk factors such as positive surgical margins, extranodal extension, pathological T3-4 primary, N2-3 nodal disease, perineural invasion or lymphovascular invasion. The adjuvant RT dose ranged from 60 to 66 Gy. For those patients with unresectable disease, definitive concurrent chemoradiotherapy (CCRT) with RT dose 6672 Gy was usually used.

For oropharyngeal or hypopharyngeal cancer patients in Taiwan, most common treatments were radiotherapy with or without chemotherapy because patients usually favor organ preservation strategies [36]. The RT dose was $66-72$ Gy for definitive CCRT. About $30 \%$ of these patients received surgical intervention [36]. Adjuvant RT or CCRT with RT dose 60-66 Gy was usually given if there were high risk factors such as positive surgical margins, extranodal extension, pathological T3-4 primary, N2-3 nodal disease, perineural invasion or lymphovascular invasion.

\section{Statistical analysis}

The Kaplan-Meier method was used for univariate analysis and the log-rank test was used to detect differences. Cox proportional hazards model and competing risk analysis were used for multivariate analysis to evaluate the association between RT and intracranial aneurysms formation. Hazard ratios (HRs) and 95\% confidence intervals (CIs) were computed after adjusting for comorbidities and sociodemographic characteristics (age, sex, income, and level of urbanization). All analyses were performed using the SAS ver. 9.4 software (SAS Institute, Cary, NC, USA).

\section{Results}

\section{General characteristics}

During 2000-2012, 70,691 head and neck patients met the inclusion criteria were included in the final analysis (Fig. 1). There were 15,257, 39,071, and 16,363 subjects in the NPC-RT, non-NPC-RT, and non-NPC-NRT groups, respectively (Table 1 ).

Among these enrolled subjects, 40 NPC-RT cases were diagnosed with intracranial aneurysms after RT. In Non-NPC-RT and Non-NPC-NRT groups, there were 36 cases and 9 cases diagnosed with intracranial aneurysms during follow-up period. Compared to Non-NPC-RT and Non-NPC-NRT groups, the NPC$\mathrm{RT}$ group had higher risk of developing intracranial aneurysms $(P<0.0001)$.
General characteristics of patients with newly diagnosed intracranial aneurysms

The incidence of intracranial aneurysms formation was $47.8,23.9$, and 10.4 per 100,000 person-years in the NPC-RT, non-NPC-RT, and non-NPC-NRT groups, respectively (Table 2 ). The NPC-RT group had a significantly higher incidence of newly formed intracranial aneurysms compared with the other two groups $(P<0.0001$; Fig. 2). Although the incidence of new intracranial aneurysms was higher in the non-NPC-RT group compared with the non-NPC-NRT group, the difference was not statistically significant $(P=0.57)$.

Among the patients with newly formed intracranial aneurysms, 77.5, 77.8, and $100.0 \%$ were male in the NPC-RT, non-NPC-RT, and non-NPC-NRT groups, respectively. The mean ages were $50.7 \pm 11.3$, $56.7 \pm 9.4$, and $53.8 \pm 13.7$ years, respectively, and the time intervals from aneurysm formation to treatment were $4.3 \pm 3.1$, $1.9 \pm 2.2$, and $5.5 \pm 3.2$ years, respectively.

\section{Factors associated with newly developed intracranial aneurysms}

Multivariate regression analysis revealed that RT was a significant risk factor for intracranial aneurysms development (Table 3). The risk of intracranial aneurysms formation was highest in the NPC-RT group ( $\mathrm{HR}=1.99$, 95\% CI: $1.23-3.21, P<0.01)$ and lowest in the nonNPC-NRT group (HR = 0.60, 95\% CI:0.26-1.35, $P=0.21$ ) . Moreover, hypertension was also associated with an increasing risk of aneurysm development $(\mathrm{HR}=2.01,95 \%$ CI: $1.22-3.31, P<0.01)$.

The mortality proportion was $32.9,55.8$, and $21.7 \%$ in the NPC-RT, non-NPC-RT, and non-NPC-NRT groups, respectively (Table 1). Because of these high mortality proportion, an association between $\mathrm{RT}$ and intracranial aneurysms development could be inferred. We performed a competing risk analysis and this adjustment yielded the same results. The NPC-RT group having the highest risk $(\mathrm{HR}=2.57,95 \% \mathrm{CI}: 1.55-4.24, P<0.001)$ and the non-NPC-NRT group having the lowest risk $(\mathrm{HR}=0.70,95 \% \mathrm{CI}: 0.32-1.56, P=0.38)$ of intracranial aneurysm development. Meanwhile, hypertension was still associated with intracranial aneurysms formation (HR $=2.14,95 \%$ CI: $1.34-3.43, P<0.01)$.

\section{Discussion}

Since intracranial aneurysms after RT was first reported in 1963, many studies have described this association. However, the majority of these were case studies without a comparison group, as the incidence of intracranial aneurysms after RT is low. Additionally, the diagnosis of radiation-induced intracranial aneurysms remains controversial due to a limited number of cases, the need for long-term follow-up after RT, a lack of statistical 


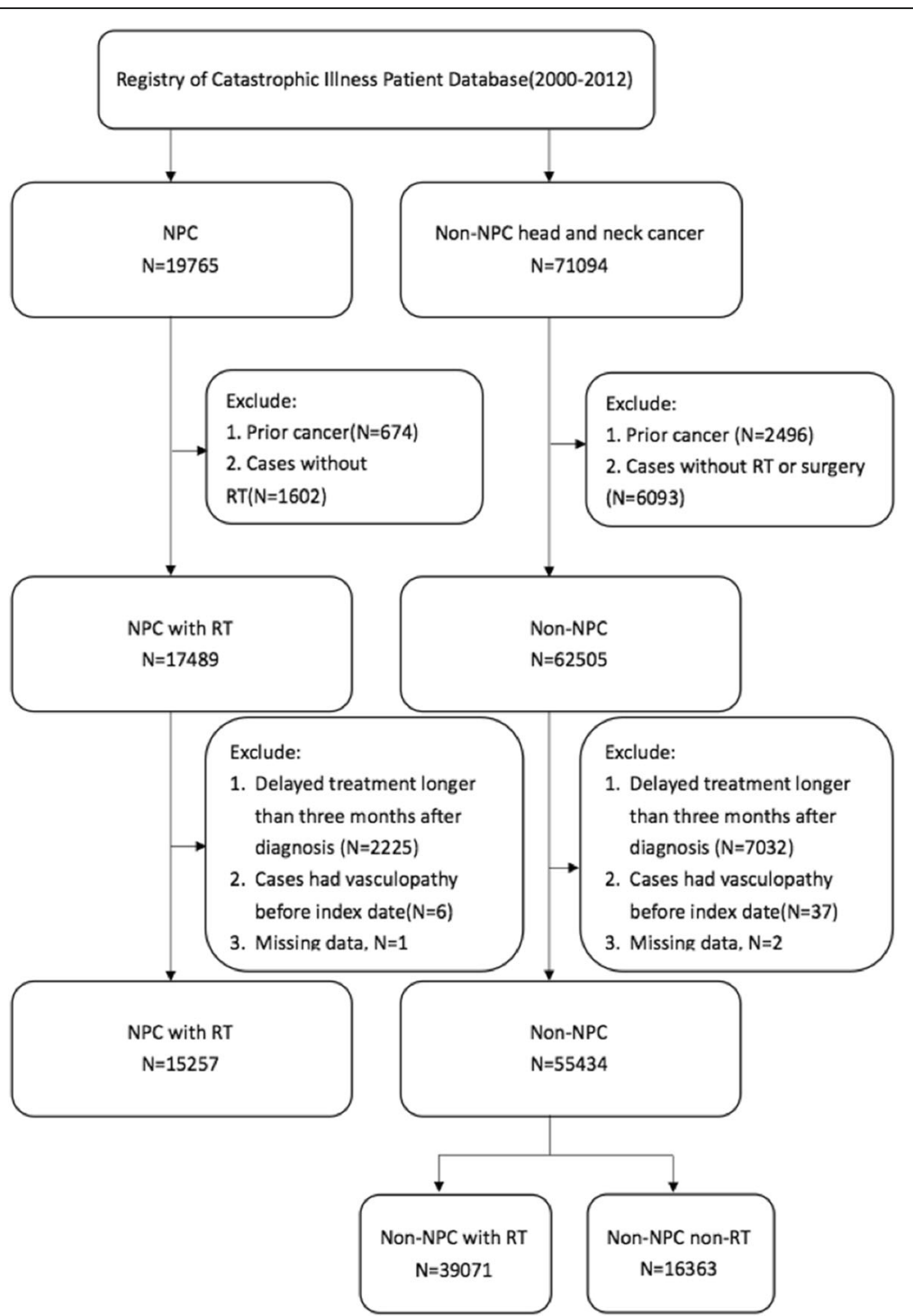

Fig. 1 Flow diagram of this nationwide-based study. Abbreviations: NPC-RT, nasopharyngeal cancer patients with radiotherapy; Non-NPC-RT, other head and neck cancer patients with radiotherapy; Non-NPC-NRT, other head and neck cancer patients without radiotherapy

analysis, and the lack of established diagnostic criteria. NHIRD was established since 1996 and includes the medical data from 26 million population. In the present study, NHIRD was used to obtain a large sample size and the long-term follow-up to explore the potential relationship between $\mathrm{RT}$ and the incidence of intracranial aneurysms formation.

The incidence of radiation-induced intracranial aneurysms is affected by many factors and is thus difficult to determine [40]. In a study by Vernooij et al., the incidence was $1.8 \%$ [41]. Meanwhile, Omura et al. reported that $19 \%$ of patients studied had steno-occlusive changes of their cerebral arteries after external radiation [42]. Cappelli et al. also reported that $17 \%$ of patients had cerebrovascular complications after RT for optic tumors
[43]. In this study, the incidence rate of intracranial aneurysms was 47.8 per 100,000 person-years in patients with NPC treated with RT. The incidence rate reported in the present study was much lower than that reported in previous studies.

This low incidence might be related to the strict criteria used in this study. First, the ICD-9 codes 4373 was used for intracranial aneurysm formation. Besides, there was no ICD-9 code for ruptured aneurysms. We used the ICD-9 procedure code for aneurysm clipping (3951) to enroll the ruptured or nonruptured aneurysm patients. Second, some patients with intracranial spontaneous subarachnoid hemorrhage (SAH) and were in a deep coma (Glasgow Coma Scale less than six) may not receive further imaging studies such as angiography or 
Table 1 Baseline characteristics of the NPC-RT, Non-NPC-RT, and Non-NPC-NRT groups

\begin{tabular}{|c|c|c|c|c|c|c|c|}
\hline \multirow[t]{2}{*}{ Variables } & \multicolumn{2}{|c|}{ NPC-RT $(n=15,257)$} & \multicolumn{2}{|c|}{ Non-NPC-RT $(n=39,071)$} & \multicolumn{2}{|c|}{ Non-NPC-NRT $(n=16,363)$} & \multirow[t]{2}{*}{$P$ value } \\
\hline & $n$ & $\%$ & $n$ & $\%$ & $n$ & $\%$ & \\
\hline \multicolumn{7}{|l|}{ Gender } & $<0.0001$ \\
\hline Male & 11,443 & 75.00 & 35,958 & 92.03 & 14,500 & 88.61 & \\
\hline Female & 3814 & 25.00 & 3113 & 7.97 & 1863 & 11.39 & \\
\hline \multicolumn{7}{|l|}{ Age, years } & $<0.0001$ \\
\hline$<45$ & 5302 & 34.75 & 8250 & 21.12 & 3530 & 21.57 & \\
\hline $45-65$ & 7949 & 52.10 & 23,536 & 60.24 & 9265 & 56.62 & \\
\hline$>65$ & 2006 & 13.15 & 7285 & 18.65 & 3568 & 21.81 & \\
\hline \multicolumn{8}{|c|}{ Comorbidities } \\
\hline \multicolumn{7}{|l|}{ Arrhythmia } & $<0.0001$ \\
\hline Yes & 1617 & 10.6 & 4361 & 11.16 & 2144 & 13.10 & \\
\hline No & 13,640 & 89.40 & 34,710 & 88.84 & 14,219 & 86.90 & \\
\hline \multicolumn{7}{|l|}{ HTN } & $<0.0001$ \\
\hline Yes & 5845 & 38.31 & 16,169 & 41.38 & 8166 & 49.91 & \\
\hline No & 9412 & 61.69 & 22,902 & 58.62 & 8197 & 50.09 & \\
\hline \multicolumn{7}{|l|}{ DM } & $<0.0001$ \\
\hline Yes & 2694 & 17.66 & 9093 & 23.27 & 4773 & 29.17 & \\
\hline No & 12,563 & 82.34 & 29,978 & 76.73 & 11,590 & 70.83 & \\
\hline \multicolumn{7}{|l|}{ COPD } & $<0.0001$ \\
\hline Yes & 2489 & 16.31 & 7198 & 18.42 & 3134 & 19.15 & \\
\hline No & 12,768 & 83.69 & 31,873 & 81.58 & 13,229 & 80.85 & \\
\hline \multicolumn{7}{|c|}{ Dyslipidemia } & $<0.0001$ \\
\hline Yes & 3837 & 25.15 & 9137 & 23.39 & 5398 & 32.99 & \\
\hline No & 11,420 & 74.85 & 29,934 & 76.61 & 10,965 & 67.01 & \\
\hline \multicolumn{7}{|c|}{ Chronic Kidney disease } & $<0.0001$ \\
\hline Yes & 647 & 4.24 & 1728 & 4.42 & 879 & 5.37 & \\
\hline No & 14,610 & 95.76 & 37,343 & 95.58 & 15,484 & 94.63 & \\
\hline \multicolumn{7}{|c|}{ Coronary artery disease } & $<0.0001$ \\
\hline Yes & 2435 & 15.96 & 6599 & 16.89 & 3742 & 22.87 & \\
\hline No & 12,822 & 84.04 & 32,472 & 83.11 & 12,621 & 77.13 & \\
\hline \multicolumn{7}{|c|}{ Heart failure } & $<0.0001$ \\
\hline Yes & 695 & 4.56 & 2219 & 5.68 & 1150 & 7.03 & \\
\hline No & 14,562 & 95.44 & 36,852 & 94.32 & 15,213 & 92.97 & \\
\hline \multicolumn{7}{|c|}{ Liver cirrhosis } & $<0.0001$ \\
\hline Yes & 443 & 2.90 & 3588 & 9.18 & 1053 & 6.44 & \\
\hline No & 14,814 & 97.10 & 35,483 & 90.82 & 15,310 & 93.56 & \\
\hline \multicolumn{7}{|c|}{ Chemotherapy } & $<0.0001$ \\
\hline Yes & 12,596 & 82.56 & 27,637 & 70.74 & 1469 & 8.98 & \\
\hline No & 2661 & 17.44 & 11,434 & 29.26 & 14,894 & 91.02 & \\
\hline \multicolumn{8}{|c|}{ Intracranial aneurysms } \\
\hline Yes & 40 & 0.26 & 36 & 0.09 & 9 & 0.06 & $<0.0001$ \\
\hline No & 15,217 & 99.74 & 39,035 & 99.91 & 16,354 & 99.94 & \\
\hline Death & 5014 & 32.86 & 21,796 & 55.79 & 3548 & 21.68 & $<0.0001$ \\
\hline
\end{tabular}


Table 2 Characteristics of patients with radiation-induced intracranial aneurysms

\begin{tabular}{llll}
\hline Variables & NPC-RT & Non-NPC-RT & Non-NPC-NRT \\
\hline Number & 40 & 36 & 9 \\
Incidence, 100,000 persons-year $(95 \% \mathrm{Cl})$ & $47.8(35.1-65.2)$ & $23.9(17.2-33.1)$ & $10.4(5.4-19.9)$ \\
Interval time, years ( \pm SD) & $4.3( \pm 3.1)$ & $1.9( \pm 2.2)$ & $5.5( \pm 3.2)$ \\
Mean age, years ( \pm SD) & $50.7( \pm 11.3)$ & $56.7( \pm 9.4)$ & $53.8( \pm 13.7)$ \\
Gender & & & $9(100.0)$ \\
Male (\%) & $31(77.5)$ & $28(77.8)$ & $0(0)$ \\
Female (\%) & $9(22.5)$ & $8(22.2)$ & \\
\hline
\end{tabular}

Abbreviations: NPC-RT nasopharyngeal cancer patients with radiotherapy, Non-NPC-RT other head and neck cancer patients with radiotherapy, Non-NPC-NRT other head and neck cancer patients without radiotherapy, $\mathrm{Cl}$ confidence interval, $S D$ standard deviation

computed tomography (CT) angiography due to unstable vital signs. Therefore, these patients were not diagnosed with intracranial aneurysms. Third, a patient diagnosed with an aneurysm may be treated with endovascular coiling instead of surgical clipping in recent years. Unlike surgical clipping, no appropriate ICD-9 codes exist for coiling. Therefore, we were unable to include patients treated with coiling or other endovascular techniques in this study. Finally, patients who developed intracranial aneurysms with no symptoms did not undergo imaging studies, and were thus not identified. Together, these circumstances may have contributed to the under-estimation and low reported incidence rate of intracranial aneurysms formation in the present study. Despite the low incidence rate presented in this study, the risk of developing an intracranial aneurysm was higher in patients with NPC than in patients with nonNPC.

The underlying reason for this significantly higher risk of intracranial aneurysm formation in NPC patients receiving $\mathrm{RT}$ may be related to the higher radiation dose to intracranial vessels during RT (Fig. 3). The clinical target volume (CTV) in NPC patients includes the entire nasopharynx, posterior third of the nasal cavity, the maxillary sinus, pterygoid fossae, parapharyngeal space, retropharyngeal lymph nodes, clivus, skull base, sphenoid sinus, and bilateral neck lymph nodes [44, 45]. For other head and neck cancers, the CTV rarely included the clivus, skull base, and sphenoid sinus unless a tumor is involved. Therefore, the intracranial vessels of the

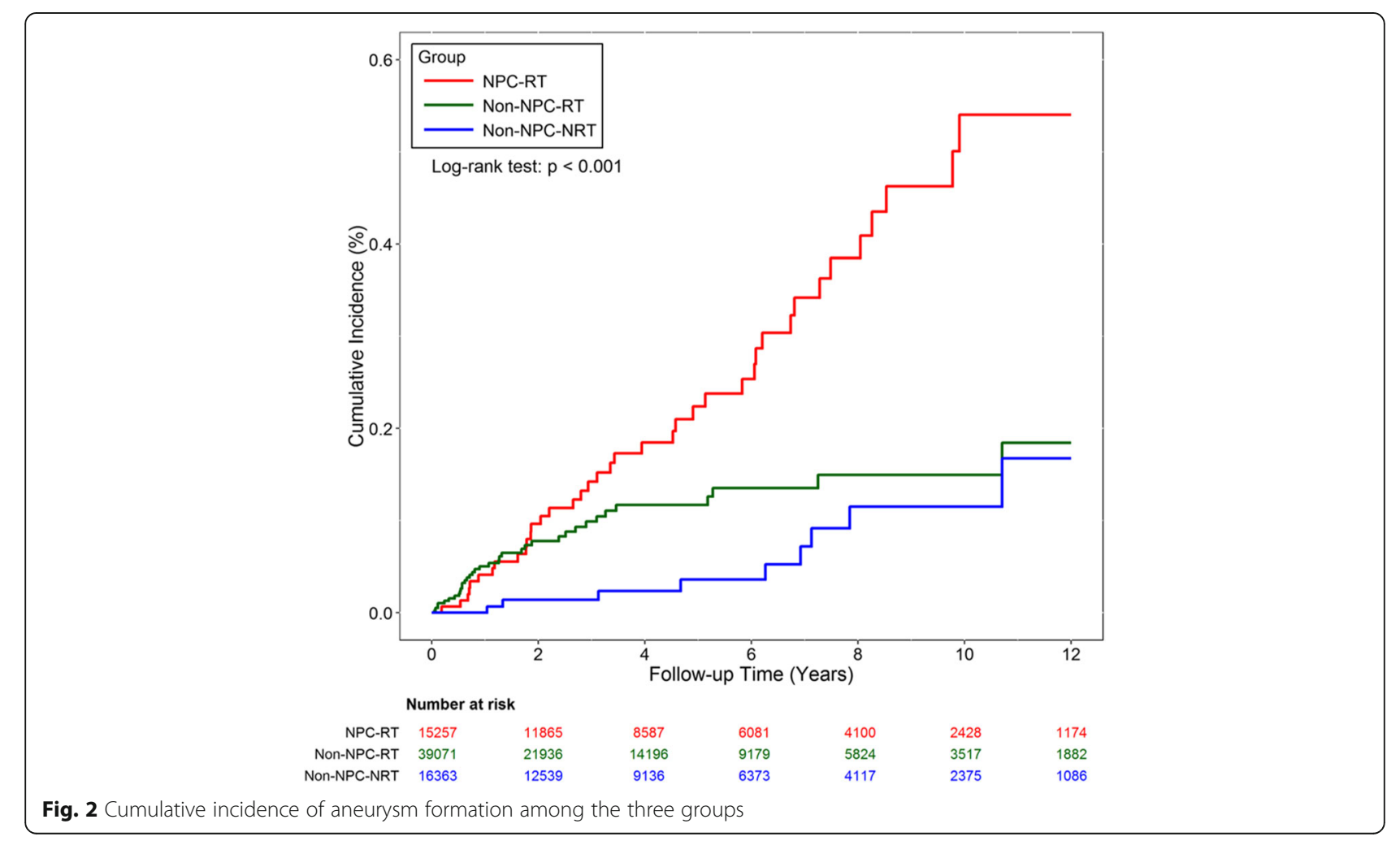


Table 3 Cox proportional hazards model and competing risk analyses

\begin{tabular}{|c|c|c|c|c|c|c|}
\hline \multirow[t]{3}{*}{ Variables } & \multicolumn{6}{|c|}{ Aneurysms formation } \\
\hline & \multicolumn{3}{|c|}{ Adjusted } & \multicolumn{3}{|c|}{ Competing risk analysis } \\
\hline & $H R$ & $95 \% \mathrm{Cl}$ & $P$ value & $\mathrm{HR}$ & $95 \% \mathrm{Cl}$ & $P$ value \\
\hline \multicolumn{7}{|l|}{ Group } \\
\hline NPC-RT & 1.99 & $1.23-3.21$ & $<0.01$ & 2.57 & $1.55-4.24$ & $<0.001$ \\
\hline Non-NPC-NRT & 0.60 & $0.26-1.35$ & 0.21 & 0.70 & $0.32-1.56$ & 0.38 \\
\hline Non-NPC-RT & 1.00 & reference & & 1.00 & reference & \\
\hline \multicolumn{7}{|l|}{ Gender } \\
\hline Male & 0.77 & $0.44-1.34$ & 0.35 & 0.71 & $0.39-1.28$ & 0.26 \\
\hline Female & 1.00 & reference & & 1.00 & reference & \\
\hline \multicolumn{7}{|l|}{ Age } \\
\hline$<45$ & 1.00 & reference & & 1.00 & reference & \\
\hline $45-65$ & 1.20 & $0.69-2.06$ & 0.52 & 1.07 & $0.64-1.80$ & 0.79 \\
\hline$>65$ & 0.97 & $0.43-2.19$ & 0.94 & 0.68 & $0.32-1.46$ & 0.32 \\
\hline \multicolumn{7}{|l|}{ Comorbidity } \\
\hline Arrhythmia & 1.08 & $0.56-2.07$ & 0.82 & 1.07 & $0.57-2.02$ & 0.83 \\
\hline HTN & 2.01 & $1.22-3.31$ & $<0.01$ & 2.14 & $1.34-3.43$ & $<0.01$ \\
\hline DM & 1.04 & $0.61-1.78$ & 0.87 & 0.99 & $0.59-1.66$ & 0.97 \\
\hline COPD & 1.07 & $0.62-1.85$ & 0.80 & 1.12 & $0.63-2.00$ & 0.69 \\
\hline Dyslipidemia & 0.88 & $0.53-1.46$ & 0.61 & 0.98 & $0.60-1.58$ & 0.92 \\
\hline CKD & 0.93 & $0.33-2.58$ & 0.88 & 0.92 & $0.32-2.64$ & 0.87 \\
\hline CAD & 1.51 & $0.88-2.61$ & 0.14 & 1.59 & $0.92-2.74$ & 0.10 \\
\hline Heart failure & 0.32 & $0.08-1.34$ & 0.12 & 0.29 & $0.07-1.20$ & 0.09 \\
\hline Liver cirrhosis & 1.41 & $0.61-3.28$ & 0.43 & 1.15 & $0.48-2.73$ & 0.76 \\
\hline \multicolumn{7}{|l|}{ Chemotherapy } \\
\hline Yes & 1.71 & $0.97-3.00$ & 0.06 & 1.37 & $0.83-2.26$ & 0.21 \\
\hline No & 1.00 & reference & & 1.00 & reference & \\
\hline
\end{tabular}

Abbreviations: NPC-RT nasopharyngeal cancer patients with radiotherapy, Non$N P C-R T$ other head and neck cancer patients with radiotherapy, Non-NPC-NRT other head and neck cancer patients without radiotherapy, HTN hypertension, $D M$ diabetes mellitus, COPD chronic obstructive pulmonary disease, $C K D$ chronic kidney disease, CAD coronary artery disease, $H R$ hazard ratio, $\mathrm{Cl}$ confidence interval

majority of NPC patients received a high radiation dose, especially the vessels in the cavernous sinus. In contrast, few non-NPC patients received high radiation doses to the intracranial vessels.

The risk of intracranial aneurysm formation was slightly higher in the non-NPC-RT group compared with the non-NPC-NRT group, but this difference was not statistically significant. As mentioned above, the intracranial vessels of non-NPC-RT group patients usually received little or no radiation dose. However, some nonNPC-RT group patients may receive high radiation dose to intracranial vessels if they had advanced disease with tumor invasion to parapharyngeal space, infratemporal fossa or skull base. In addition, the radiation effect could potentially cause vascular abnormality for non-NPC-RT group patients receiving little radiation dose to intracranial vessels. This systematic effect of radiation has been described in previous studies [46-48]. Maduro et al. reported a risk of myocardial infarction in patients with cervical cancer after RT, and Nilsson et al. reported an increased risk of stroke in patients with breast cancer after RT.

The time interval needed to induce intracranial aneurysms formation after RT is another important issue for clinical physician. In previous studies, the time interval ranged from 6 months to 8 years [43, 49, 50]. In a literature review by Nanney et al., the average interval ranged from 5.71 years in a stereotactic radiosurgery (SRS) group to 11.24 years in a focused radiation group. They found that elderly individuals had a shorter interval than did younger patients. Thus, this time interval may be related to a higher level of atherosclerosis, a higher dose in a limited field, or a larger exposure field. The interval between RT and aneurysm formation in the present study was $4.3 \pm 3.1$ years; this was similar to intervals reported in other studies. However, in the non-NPC-RT group, the time interval was only $1.9 \pm 2.2$ years. This short interval may be related to the high mortality proportion (55.8\%) in the non-NPC-RT group.

Malignancy-related death may lower the reported incidence of radiation-induced intracranial aneurysms. Therefore, competing risk analysis was used to more precisely explore the potential risk factors involved. After adjusting for risk of cancer-related death, patients in the NPC-RT group still had the highest risk of developing radiationinduced intracranial aneurysms (HR $=2.57,95 \%$ CI: 1.55 $4.24, P<0.001)$. Patients with non-NPC who were treated with RT had a higher risk of developing intracranial aneurysms than did those who did not receive RT, but this difference was not statistically significant (HR $=0.70,95 \%$ CI: $0.32-1.56, P=0.38)$. Moreover, patients with hypertension had a higher risk of developing newly diagnosed intracranial aneurysms $(\mathrm{HR}=2.14,95 \% \mathrm{CI}: 1.34-3.43$, $P<0.01)$ and the association between hypertension and intracranial aneurysms formation has been well documented in other study [51]. Another interesting finding of this study was related to gender. Traditionally, females have been considered to have a higher risk of intracranial aneurysm formation [52]; however, males may have a higher risk of developing radiation-induced intracranial aneurysms [24]. We obtained similar results in our study, as the majority of patients who developed aneurysms was male. However, based on multiple regression analysis, male gender was not significantly associated with intracranial aneurysms formation ( $\mathrm{HR}=0.71,95 \% \mathrm{CI}$ : $0.39-1.28$, $P=0.26)$.

There are several limitations to our study. First, RT techniques including two-dimensional RT, three-dimensional conformal RT or intensity modulated radiation therapy 


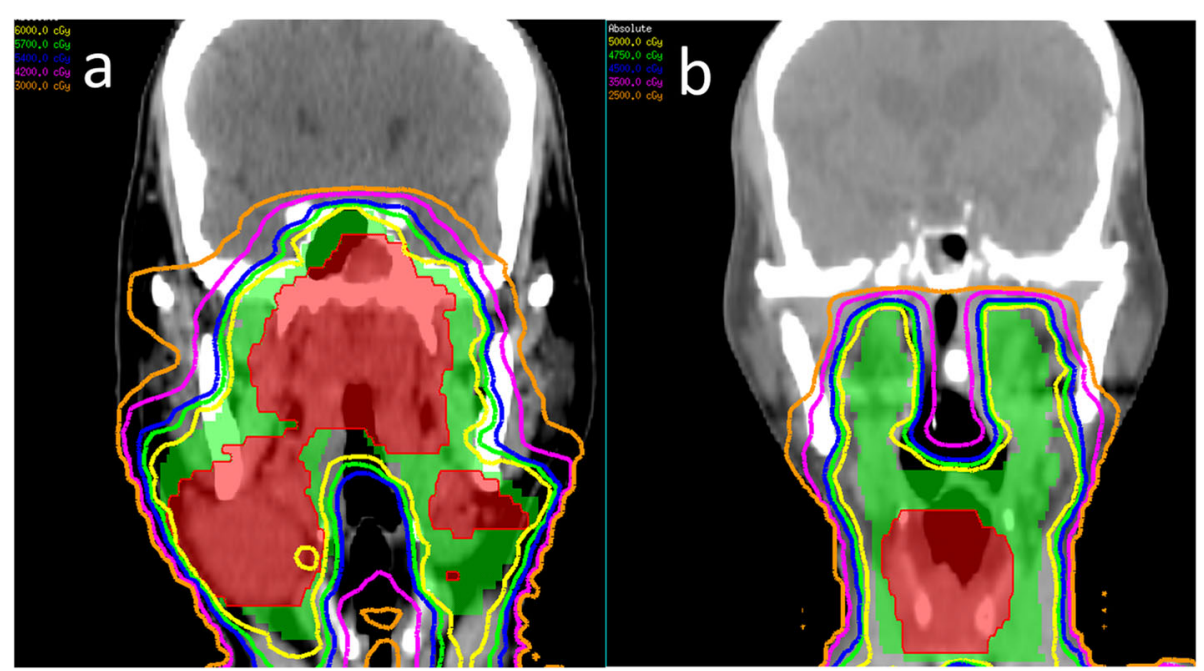

Fig. 3 a Nasopharyngeal cancer, CT3N2M0, stage III. A 60-Gy dose was prescribed to the entire nasopharynx, posterior third of the nasal cavity and maxillary sinus, pterygoid fossae, parapharyngeal space, retropharyngeal lymph nodes, clivus, skull base, sphenoid sinus, and bilateral upper neck lymph nodes. A 70-Gy dose was prescribed to the gross tumor and lymphadenopathies areas (red area). b Supraglottic cancer, cT3NOM0, stage III. A 50-Gy dose was prescribed to the retropharyngeal lymph nodes and bilateral neck lymph nodes. A 70-Gy dose was prescribed to the gross tumor area (red area)

(IMRT) cannot be differentiated by using the NHIRD. Moreover, each patient may receive different radiation dose. However, total dose of 66-74 Gy in 1.8-2.12 Gy per fraction were usually prescribed for head and neck patients with gross tumor and total dose of $60-66$ Gy in $1.8-2$ Gy per fraction were usually prescribed for head and neck patients in adjuvant treatments. Therefore, the total radiation dose differences between NPC-RT and non-NPC-RT groups were limited. Consequently, we were able to compare the effect of radiation based only on the different radiation fields between these two groups. Next, we were unable to retrieve imaging data. Unlike general aneurysms, radiation-induced intracranial aneurysms can originate from the arterial wall rather than a branching site [13]. This uncommon location may be related to vessel wall degradation caused by radiation [24]. In addition to aneurysm location, the shape of an aneurysm may also be affected by RT. Radiation-induced intracranial aneurysms are more likely to be fusiform or pseudoaneurysms [40]. Because no detailed imaging data are included in the NHIRD, it was unable to confirm the locations and shapes of aneurysms in this study. Cahan et al. [53] mentioned that radiationinduced tumors should be located within the radiation field and that they should not present before radiation. While the systemic effects of radiation should be considered, detailed imaging reports are required to improve diagnostic accuracy. Finally, other risk factors of developing aneurysms formation including smoking, alcohol abuse and family history of intracranial aneurysms were not recorded in NHIRD [51, 54, 55]. It was unable to analyze the confounding effect of these well-known risk factors. Because of these limitations, more studies were needed to determine the diagnostic criteria of radiation-induced intracranial aneurysms.

\section{Conclusions}

In the present study, NPC patients treated with RT were at higher risk of developing intracranial aneurysms than were patients with non-NPC, when treated with or without RT. Moreover, the low incidence of RT-induced intracranial aneurysms in this study was under estimation and the real number would be higher. While considering the catastrophic outcome after intracranial aneurysm rupture, the long-term follow-up is warranted if patients have a history of high radiation dose exposure to intracranial vessels.

\section{Abbreviations}

CAD: Coronary artery disease; Cl: Confidence interval; CKD: Chronic kidney disease; CT: Computed tomography; CTV: Clinical target volume; HR: Hazard ratio; IMRT: Intensity modulated radiation therapy; NHIRD: The National Health Insurance Research Database; NPC: Nasopharyngeal carcinoma; RT: Radiotherapy; SAH: Subarachnoid hemorrhage; SRS: Stereotactic radiosurgery

\section{Acknowledgments}

We thank the Health Information and Epidemiology Laboratory of Chang Gung Memorial Hospital, Chia-Yi Branch for their comments and assistance with data analysis. This study was based on the National Health Insurance Research Database provided by the Central Bureau of National Health Insurance, the Department of Health, and managed by the National Health Research Institutes. The interpretation and conclusions contained herein do not represent those of the Bureau of National Health Insurance, Department of Health, or National Health Research Institutes.

\section{Authors' contributions}

WHY, CHL, TCW, and CYC conceptualized the article; WHY, CHL, and YHY drafted and designed the manuscript; PCC, YHY, and KJC analyzed and interpreted the data; and PCC performed a critical revision of the manuscript. All authors read and approved the final manuscript. 


\section{Funding}

This study was supported by a grant from Chang Gung Memorial Hospital, Chia-Yi Branch (No. CLRPG6G0041).

\section{Availability of data and materials}

The datasets generated during and analysed during the current study are available from the corresponding author on reasonable request.

\section{Ethics approval and consent to participate}

This study adhered to strict confidentiality guidelines in accordance with regulations regarding personal electronic data protection. It was approved by the Chang Gung Medical Foundation Institutional Review Board (No. 201700121B1). All data were analyzed anonymously; the requirement for informed consent was waived by the institutional review board.

\section{Consent for publication}

Not applicable.

\section{Competing interests}

The authors declare that they have no competing interests.

\section{Author details}

${ }^{1}$ Division of Neurosurgery, Department of Surgery, Chang Gung Memoria Hospital, Chia-Yi, Taiwan. ${ }^{2}$ Department of Traditional Chinese Medicine, Chang Gung Memorial Hospital, Chia-Yi, Taiwan. ${ }^{3}$ Health Information and Epidemiology Laboratory of Chang Gung Memorial Hospital, Chiayi, Taiwan. ${ }^{4}$ School of Traditional Chinese Medicine, College of Medicine, Chang Gung University, Taoyuan, Taiwan. ${ }^{5}$ Institute of Occupational Medicine and Industrial Hygiene, National Taiwan University College of Public Health, Taipei, Taiwan. ${ }^{6}$ Department of Environmental and Occupational Medicine, National Taiwan University Hospital and National Taiwan University College of Medicine, Taipei, Taiwan. ${ }^{7}$ Department of Radiation Oncology, Chang Gung Memorial Hospital, No 6, West Section, Chia-Pu Road, Putz City, Chia-Yi, Taiwan613.

Received: 29 December 2017 Accepted: 29 May 2019

Published online: 04 June 2019

\section{References}

1. Huang Y-S, Lee C-C, Chang T-S, Ho H-C, Su Y-C, Hung S-K, Lee M-S, Chou P, Chang $\mathrm{Y}-\mathrm{H}$, Lee $\mathrm{C}-\mathrm{C}$. Increased risk of stroke in young head and neck cancer patients treated with radiotherapy or chemotherapy. Oral Oncol. 2011;47(11):1092-7.

2. Brown PD, Foote RL, McLaughlin MP, Halyard MY, Ballman KV, Collie AC, Miller RC, Flemming KD, Hallett JW. A historical prospective cohort study of carotid artery stenosis after radiotherapy for head and neck malignancies. Int J Radiat Oncol Biol Phys. 2005;63(5):1361-7.

3. Periard D, Boulanger CM, Eyer S, Amabile N, Pugin P, Gerschheimer C, Hayoz D. Are circulating endothelial-derived and platelet-derived microparticles a pathogenic factor in the cisplatin-induced stroke? Stroke. 2007;38(5):1636-8.

4. Li S-H, Chen W-H, Tang Y, Rau K-M, Chen Y-Y, Huang T-L, Liu J-S, Huang C $\mathrm{H}$. Incidence of ischemic stroke post-chemotherapy: a retrospective review of 10,963 patients. Clin Neurol Neurosurg. 2006;108(2):150-6.

5. Scott AS, Parr LA, Johnstone PA. Risk of cerebrovascular events after neck and supraclavicular radiotherapy: a systematic review. Radiother Oncol. 2009;90(2):163-5.

6. Huang TL, Hsu HC, Chen HC, Lin HC, Chien CY, Fang FM, Huang CC, Chang HW, Chang WN, Huang CR. Long-term effects on carotid intima-media thickness after radiotherapy in patients with nasopharyngeal carcinoma. Radiat Oncol. 2013;8(1):261.

7. Nilsson G, Holmberg L, Garmo H, Terent A, Blomqvist C. Increased incidence of stroke in women with breast cancer. Eur J Cancer. 2005;41(3):423-9.

8. Yamamoto $M$, Ide $M$, Jimbo M, Ono Y. Middle cerebral artery stenosis caused by relatively low-dose irradiation with stereotactic radiosurgery for cerebral arteriovenous malformations: case report. Neurosurgery. 1997;41(2):474-8.

9. O'connor MM, Mayberg MR. Effects of radiation on cerebral vasculature: a review. Neurosurgery. 2000;46(1):138-51.

10. Darmody W, Thomas L, Gurdjian E. Postirradiation vascular insufficiency syndrome: CASE report. Detroit: Wayne State Univ; 1967.
11. Lee K, Hodes PJ. Intracranial ischemic lesions. Radiol Clin North Am. 1967;5(3):353-60.

12. Azzarelli B, Moore J, Gilmor R, Muller J, Edwards M, Mealey J. Multiple fusiform intracranial aneurysms following curative radiation therapy for suprasellar germinoma: case report. J Neurosurg. 1984;61(6):1141-5.

13. Benson PJ, Sung JH. Cerebral aneurysms following radiotherapy for medulloblastoma. J Neurosurg. 1989;70(4):545-50.

14. Casey AT, Marsh HT, Uttley D. Intracranial aneurysm formation following radiotherapy. Br J Neurosurg. 1993;7(5):575-9.

15. Gomori JM, Levy P, Weshler Z. Radiation-induced aneurysm of the basilar artery—a case report. Angiology. 1987;38(2):147-50.

16. Holodny Al, Deck M, Petito CK. Induction and subsequent rupture of aneurysms of the circle of Willis after radiation therapy in Ehlers-Danlos syndrome: a plausible hypothesis. Am J Neuroradiol. 1996;17(2):226-32.

17. Jensen $F$, Wagner A. Intracranial aneurysm following radiation therapy for medulloblastoma: a case report and review of the literature. Acta Radiol. 1997;38(1):37-42.

18. John D, Porter M, Van Hasselt C. Beware bleeding from the ear. J Laryngol Otol. 1993;107(02):137-9.

19. McConachie N, Jacobson I. Bilateral aneurysms of the cavernous internal carotid arteries following yttrium-90 implantation. Neuroradiology. 1994;36(8):611-3.

20. Moriyama T, Shigemori M, Hirohata Y, Konishi J, Tokunaga T, Kuramoto S. Multiple intracranial aneurysms following radiation therapy for pituitary adenoma; a case report. No Shinkei Geka. 1992;20(4):487-92.

21. Nishi T, Matsukado Y, Kodama T, Hiraki T. Multiple intracranial aneurysms following radiation therapy for pituitary adenoma. Neurol Med Chir. 1987;27(3):224-8.

22. Scodary D, Tew J, Thomas G, Tomsick T, Liwnicz B. Radiation-induced cerebral aneurysms. Acta Neurochir. 1990;102(3):141-4.

23. Maruyama K, Mishima K, Saito N, Fujimaki T, Sasaki T, Kirino T. Radiationinduced aneurysm and moyamoya vessels presenting with subarachnoid haemorrhage. Acta Neurochir. 2000;142(2):139-43.

24. Nanney AD, El Tecle NE, El Ahmadieh TY, Daou MR, Ivan ENB, Marymont $\mathrm{MH}$, Batjer HH, Bendok BR. Intracranial aneurysms in previously irradiated fields: literature review and case report. World neurosurgery. 2014;81(3):511-9.

25. Abla AA, Lawton MT, McDermott MW. Intracranial aneurysm formation following radiation. World neurosurgery. 2014;81(3):492-3.

26. Sanchez-Mejia RO, McDermott MW, Tan J, Kim H, Young WL, Lawton MT. Radiosurgery facilitates resection of brain arteriovenous malformations and reduces surgical morbidity. Neurosurgery. 2009;64(2):231.

27. Ackerman LV. The pathology of radiation effect of normal and neoplastic tissue: JANEWAY lecture 1971. Am J Roentgenol. 1972;114(3):446-59.

28. Brant-Zawadzki M, Anderson M, DeArmond S, Conley F, Jahnke R. Radiationinduced large intracranial vessel occlusive vasculopathy. Am J Roentgenol. 1980;134(1):51-5.

29. Conomy JP, Kellermeyer RW. Delayed cerebrovascular consequences of therapeutic radiation. A clinicopathologic study of a stroke associated with radiation-related carotid arteriopathy. Cancer. 1975;36(5):1702-8.

30. Fajardo L, Berthrong M. Vascular lesions following radiation. Pathol Annu. 1987;23:297-330.

31. Gajdusek CM, Tian H, London S, Zhou D, Rasey J, Mayberg MR. Gamma radiation effect on vascular smooth muscle cells in culture. Int J Radiat Oncol Biol Phys. 1996;36(4):821-8.

32. Kallfass E, Krämling H-J, Schultz-Hector S. Early inflammatory reaction of the rabbit coeliac artery wall after combined intraoperative (IORT) and external (ERT) irradiation. Radiother Oncol. 1996;39(2):167-78.

33. Starke RM, Yen C-P, Ding D, Sheehan JP. A practical grading scale for predicting outcome after radiosurgery for arteriovenous malformations: analysis of 1012 treated patients: clinical article. J Neurosurg. 2013;119(4):981-7.

34. Yen C-P, Sheehan JP, Schwyzer L, Schlesinger D. Hemorrhage risk of cerebral arteriovenous malformations before and during the latency period after GAMMA knife radiosurgery. Stroke. 2011. https://www.doi.org/10.1161/ STROKEAHA.110.602706.

35. Ye J, Rong $X$, Xiang $Y$, Xing $Y$, Tang $Y$. A study of radiation-induced cerebral vascular injury in nasopharyngeal carcinoma patients with radiation-induced temporal lobe necrosis. PLoS One. 2012;7(8):e42890.

36. Health Promotion Administration, Ministry of Health and Welfare, Taiwan. Cancer Registry Annual Report 2014. Available at: https://www.hpa.gov.tw/ Pages/Detail.aspx?nodeid=269\&pid=7330. [Accessed 2017/11/10]. 
37. Hsin CH, Chen TH, Liang KL, Tseng HC, Liu WS. Postirradiation otitis media with effusion in nasopharyngeal carcinoma patients treated by intensitymodulated radiotherapy. Laryngoscope. 2013;123(9):2148-53.

38. Fang F-M, Chien C-Y, Tsai W-L, Chen H-C, Hsu H-C, Lui C-C, Huang T-L, Huang H-Y. Quality of life and survival outcome for patients with nasopharyngeal carcinoma receiving three-dimensional conformal radiotherapy vs. intensity-modulated radiotherapy — a longitudinal study. Int J Radiat Oncol Biol Phys. 2008;72(2):356-64.

39. Chang J, Ko J-Y, Hong R-L. Recent advances in the treatment of nasopharyngeal carcinoma. Journal of the Formosan Medical Association= Taiwan yi zhi. 2004;103(7):496-510.

40. Sheehan JP, Starke RM. Aneurysm formation associated with ionizing radiation. World neurosurgery. 2014;81(3):487-9.

41. Vernooij MW, Ikram MA, Tanghe HL, Vincent AJ, Hofman A, Krestin GP, Niessen WJ, Breteler MM, van der Lugt A. Incidental findings on brain MRI in the general population. N Engl J Med. 2007;357(18):1821-8.

42. Omura M, Aida N, Sekido K, Kakehi M, Matsubara S. Large intracranial vessel occlusive vasculopathy after radiation therapy in children: clinical features and usefulness of magnetic resonance imaging. Int J Radiat Oncol Biol Phys. 1997;38(2):241-9.

43. Cappelli C, Grill J, Raquin M, Pierre-Kahn A, Lellouch-Tubiana A, TerrierLacombe M, Habrand J, Couanet D, Brauner R, Rodriguez D. Long term follow up of 69 patients treated for optic pathway tumours before the chemotherapy era. Arch Dis Child. 1998;79(4):334-8.

44. Lai C-H, Chen M-F, Fang F-M, Chen W-C. Estimation of life expectancy and quality-adjusted life expectancy in non-metastatic nasopharyngeal cancer patients treated by intensity-modulated radiotherapy with or without chemotherapy. Oral Oncol. 2014;50(7):646-50.

45. Lee N, Harris J, Garden AS, Straube W, Glisson B, Xia P, Bosch W, Morrison WH, Quivey J, Thorstad W. Intensity-modulated radiation therapy with or without chemotherapy for nasopharyngeal carcinoma: radiation therapy oncology group phase II trial 0225. J Clin Oncol. 2009;27(22):3684-90.

46. Tsai S-J, Huang Y-S, Tung C-H, Lee C-C, Lee M-S, Chiou W-Y, Lin H-Y, Hsu FC, Tsai C-H, Su Y-C. Increased risk of ischemic stroke in cervical cancer patients: a nationwide population-based study. Radiat Oncol. 2013;8(1):41.

47. Jacobson G, Lammli J, Zamba G, Hua L, Goodheart MJ. Thromboembolic events in patients with cervical carcinoma: incidence and effect on survival. Gynecol Oncol. 2009;113(2):240-4.

48. Al-Badawi IA, Al-Aker M, AlSubhi J, Salem H, Abduljabbar A, Balaraj K, Munkarah A. Laparoscopic ovarian transposition before pelvic irradiation: a Saudi tertiary center experience. Int J Gynecol Cancer. 2010;20(6):1082-6.

49. Bitzer $\mathrm{M}$, Topka H. Progressive cerebral occlusive disease after radiation therapy. Stroke. 1995;26(1):131-6

50. Pereira P, Cerejo A, Cruz J, Vaz R. Intracranial aneurysm and vasculopathy after surgery and radiation therapy for craniopharyngioma: case report. Neurosurgery. 2002;50(4):885-8.

51. Bonita R. Cigarette smoking, hypertension and the risk of subarachnoid hemorrhage: a population-based case-control study. Stroke. 1986;17(5):831-5

52. de Rooij NK, Linn FH, van der Plas JA, Algra A, Rinkel GJ. Incidence of subarachnoid haemorrhage: a systematic review with emphasis on region, age, gender and time trends. J Neurol Neurosurg Psychiatry. 2007;78(12):1365-72.

53. Cahan WG, Woodard HQ, Higinbotham NL, Stewart FW, Coley BL. Sarcoma arising in irradiated bone. Cancer. 1998;82(1):8-34.

54. Wirth F. Surgical treatment of incidental intracranial aneurysms. Clin Neurosurg. 1985:33:125-35

55. Connolly ES, Rabinstein AA, Carhuapoma JR, Derdeyn CP, Dion J, Higashida RT, Hoh BL, Kirkness CJ, Naidech AM, Ogilvy CS. Guidelines for the management of aneurysmal subarachnoid hemorrhage. Stroke. 2012. https://www.doi.org/10.1161/STR.0b013e3182587839.

\section{Publisher's Note}

Springer Nature remains neutral with regard to jurisdictional claims in published maps and institutional affiliations.

\section{Ready to submit your research? Choose BMC and benefit from:}

- fast, convenient online submission

- thorough peer review by experienced researchers in your field

- rapid publication on acceptance

- support for research data, including large and complex data types

- gold Open Access which fosters wider collaboration and increased citations

- maximum visibility for your research: over $100 \mathrm{M}$ website views per year

At BMC, research is always in progress.

Learn more biomedcentral.com/submissions 